\title{
Common carotid intima-media thickness in acute ischemic stroke: $A$ case control study
}

\author{
Ratnakar Sahoo, M. Vamshi Krishna, D. K. S. Subrahmaniyan, T. K. Dutta, S. Elangovan ${ }^{1}$ \\ Departments of Medicine and ${ }^{1}$ Radiodiagnosis, Jawaharlal Institute of Postgraduate Medical Education and Research (JIPMER), \\ Pondicherry, India
}

\author{
Address for correspondence: \\ Dr. Ratnakar Sahoo, \\ Flat. No. B-35, Manu Apartment, \\ Mayur Vihar, Phase-l, \\ New Delhi - 110 091, India. \\ E-mail: drksahoo@gmail.com.
}

PMID: 19934564

DOI: $10.4103 / 0028-3886.57822$

\begin{abstract}
Stroke is the third leading cause of mortality worldwide. Combined carotid intima-media thickness (CIMT) is a marker of atherosclerosis and is also a predictor for ischemic stroke. We determined the frequency of CIMT in patients with acute ischemic stroke and in matched controls and also the risk factors for CIMT. Sixty patients with ischemic stroke diagnosed by computer tomography (CT) scan and 50 controls matched by age, gender, diabetes, and hypertension were studied. Subjects in both groups underwent carotid duplex scanning (ACUSON $128 \times$ P/l 0 machine) with a $7.5 \mathrm{MHz}$ linear superficial array probe in B-mode to determine the CIMT and presence of plaques. The mean age in the patient group was 62 years and $63.3 \%$ were males. The average CIMT in the patient group was $0.798 \mathrm{~mm}$ and it was $0.6 \mathrm{~mm}$ in the control group $(P<0.000 \mathrm{l})$. Patients with carotid plaque had significantly increased IMT $(0.95 \pm 0.22)$ when compared to patients without plaques $(0.71 \pm 0.12)(P<0.001)$. When the differences in mean IMT were compared among the different age groups in the patient group, there was significance $(P<0.05)$. In this study the CIMT was independently associated with increasing age and with the presence of carotid plaques.
\end{abstract}

Key words: Atherosclerosis, stroke, diabetes mellitus, hypertension, smoking, age, carotid intima media thickness

\section{Introduction}

Stroke, both ischemic and hemorrhagic, is a common and devastating disorder. Currently, ischemic heart disease and stroke are the leading causes of mortality worldwide and more than $80 \%$ of deaths occurring in the low and the middle income countries. ${ }^{[1]}$ The incidence of stroke increases with increasing age and with the growing elderly population worldwide, the number of patients with stroke are likely to increase. ${ }^{[1,2]}$

In most of the ischemic strokes the underlying pathophysiology is atherosclerosis. The risk factors for stroke are modifi able and non-modifi able. The modifi able risk factors are mostly related to the atherosclerotic burden and include diabetes, hypertension, smoking, and hyperlipidemia. ${ }^{[3,4]}$ Several risk prediction scoring systems have been evolved to identify individuals with high risk. However, most of these scoring systems have some limitations.The carotid intima-media thickness (CIMT) has emerged as a reliable independent marker of cardiovascular disease. We studied the the CIMT in patients with acute ischemic stroke.

\section{Materials and Methods}

The study subjects included 60 patients aged above 45 years with acute ischemic stroke confirmed by computer tomography (CT) scan and 50 controls matched by age, gender, diabetes, and hypertension. The study period was between August 2005 and July 2007. This study has the approval of the Institute Ethics committee. The data collected included demographic profile, neuralgic findings, vascular risk factors, and prior history 
of atherosclerotic disease. Smokers were categorized into smokers (currently smoking), exsmokers (history of previous smoking), and nonsmokers (never smoked in life). Patients with valvular heart disease, thrombophilic states, stroke of more than two weeks duration and patients on statin therapy for more than one year for any indication were excluded from the study. The size, location, and number of infarcts were noted. Electrocardiography and echocardiography were performed for all patients to quantify the cardiac function and to rule out any valvular disease. Other investigations performed were the lipid profile and relevant tests for diabetes and hypertension. In control group echocardiography and other investigations were undertaken if there were any specific indications. All patients with acute ischemic stroke received standard treatment.

\section{Carotid measurements}

The CIMT measurements were made using an ACUSON $128 \times \mathrm{P} / 10$ machine with a $7.5 \mathrm{MHz}$ linear superfi cial array probe in B-mode. All readings were taken and interpreted by the same investigator. The far wall IMT was measured as the distance between two echoic lines separated by anechoic space as validated by Pignoli et al., ${ }^{[5]}$ [Figure 1]. The point of measurement was taken $1 \mathrm{~cm}$ proximal to the carotid bulb at the site of maximal thickness. Six readings were taken in each carotid artery, avoiding the areas having plaques. The thickness was measured manually and recorded, using electronic calipers. The mean of the maximum IMT was taken as the largest value among all the 12 readings. The ultrasound machine used had a sensitivity range of $0.1 \mathrm{~mm}$ i.e., each division was equivalent to $0.1 \mathrm{~mm}$.

The presence and number of plaques was quantified in both the carotids. A plaque was defined as a focal thickening of $50 \%$ greater [Figure 1] than the surrounding area or greater than $1.5 \mathrm{~mm}$. Each carotid was scanned for the number and thickness of plaques. Similar readings were taken among the controls.

\section{Lipid profile}

The lipid fractions were measured in both the patients and controls. First, the serum was separated into total cholesterol and triglyceride fractions. The very-lowdensity lipoprotein (VLDL) fraction was calculated as one-fifth of the triglyceride level. The high-density lipid (HDL) level was estimated by precipitating the cholesterol fraction. The low-density lipid (LDL) value was then calculated by subtracting the sum of the HDL and VLDL from the total cholesterol according to the Friedeward formula.

\section{Statistical analysis}

All calculations were performed using the Microsoft Excel program, 2004 edition and the GraphPad InStat

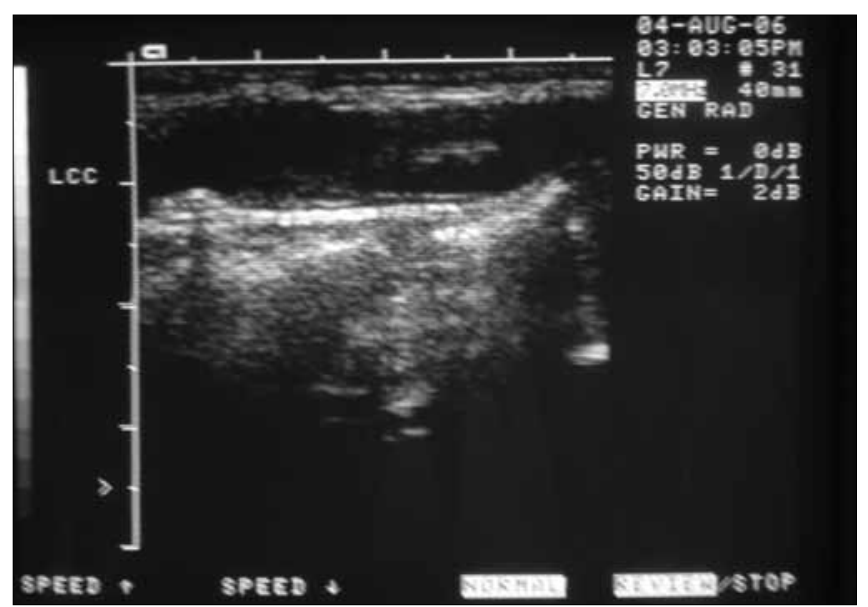

Figure1: Carotid ultrasound depicting IMT and plaque

3 program. The demographic profile of the cases and controls were analyzed using unpaired ' $t$ ' test if the parameter passed the normality test. Otherwise, the Mann-Whitney test was used. The two groups were compared with respect to the mean age, sex distribution, presence of diabetes, hypertension and smoking, and past history of ischemic heart disease and stroke. The CIMT was compared between the cases and controls using the Mann-Whitney test. Subgroup analysis of the distribution of IMT across various age groups was also performed using MannWhitney test since the distribution of data did not pass the normality test. Univariate analysis was done to determine the relationship of individual risk factors such as age, gender, diabetes, hypertension, and past history of coronary artery disease and cerebrovascular disease. IMT was separately calculated in the groups of patients with and without the risk factor and then compared using Mann-Whitney test. The two groups were analyzed with respect to presence of plaques. A separate analysis was performed to study if the IMT in patients with carotid plaques was significantly different from that among cases without plaques. Both the patients with and without plaques were separately analyzed in the patient group and controls to see if the difference in the IMT could be attributed to the presence of plaques alone.The two groups were also analyzed with respect to different lipid fractions. The strength of correlation between the various lipid fractions and the IMT was separately calculated using the Spearman's correlation test.

\section{Results}

The mean age of the patient group was 60.22 years and there were $37(62 \%)$ males. There were no significant differences in the base-line characteristics among patients and controls [Table 1]. All the 60 patients with ischemic stroke had nonhemorrhagic infaction on CT scan. The 
neurologic findings included hemiplegia in $88 \%$, aphasia in $52 \%$, faciobrachial monoplegia in $5 \%$.

\section{Carotid intima-media measurements}

In patient group the mean CIMT was $0.782 \pm 0.19 \mathrm{~mm}$ (range $0.5-1.5 \mathrm{~mm}$ ) and it was $0.594 \pm 0.98 \mathrm{~mm}$ (range $0.4-0.9 \mathrm{~mm})$ in the controls $(P<0.0001)$. This difference was also significant in the subgroup analysis by risk factors hypertension, diabetes, and smoking between patients and controls [Table 2]. The differences in the mean IMT between males $(0.767 \pm 0.18 \mathrm{~mm})$ and females $(0.787 \pm 0.22 \mathrm{~mm})$ in the patient goup was not significant. However, the difference was significant in both the genders when compared to controls $(P<0.001)$. When the differences in mean IMT were compared among the different age groups in the patient group, there was significance $(P<0.05)$. The number of subjects with history of stroke or TIA was $9(15 \%)$ in the patient group and $3(6 \%)$ in the control group $(P>0.193)$.

\begin{tabular}{lcc}
\hline \multicolumn{3}{l}{ Table 1: Baseline characteristics of patient and controls } \\
\hline Parameter & $\mathrm{N}=60(\%)$ & $\mathrm{N}=50(\%)$ \\
\hline Number of males & $37(61.7)$ & $29(58)$ \\
Number of females & $23(38.3)$ & $21(42)$ \\
Mean age (yrs) & $60.22 \pm 7.48$ & $60.58 \pm 7.56$ \\
& $(46-80)$ & $(47-78)$ \\
Number with diabetes & $11(18.3)$ & $10(20)$ \\
Number with hypertension & $10(16.7)$ & $8(16)$ \\
Number of smokers & $20(33.3)$ & $10(20)$ \\
Previous h/o CAD & $3(5 \%)$ & $4(8)$ \\
Previous h/o CVA/TIA & $9(15)$ & $3(6)$ \\
\hline
\end{tabular}

Table 2: IMT distribution among patients and controls

\begin{tabular}{|c|c|c|c|}
\hline IMT in mm & Cases & Controls & $P$ value \\
\hline Overall IMT & $\begin{array}{l}0.782 \pm 0.19 \\
(0.5-1.5 \mathrm{~mm})\end{array}$ & $\begin{array}{c}0.594 \pm 0.098 \\
(0.4-0.9 \mathrm{~mm})\end{array}$ & $<0.0001$ \\
\hline $\begin{array}{l}\text { IMT in patients } \\
\text { with diabetes }\end{array}$ & $\begin{array}{c}0.818 \pm 0.21 \\
n=11\end{array}$ & $\begin{array}{c}63 \pm 0.08 \\
n=10\end{array}$ & 0.0179 \\
\hline $\begin{array}{l}\text { IMT in patients } \\
\text { with hypertension }\end{array}$ & $\begin{array}{c}0.88 \pm 0.26 \\
n=10\end{array}$ & $\begin{array}{c}0.612 \pm 0.11 \\
n=8\end{array}$ & 0.013 \\
\hline IMT in smokers & $\begin{array}{c}0.83 \pm 0.21 \\
\mathrm{n}=20\end{array}$ & $\begin{aligned} 0.6 & \pm 0.07 \\
\mathrm{n} & =10\end{aligned}$ & 0.0001 \\
\hline $\begin{array}{l}\text { IMT in patients } \\
\text { with IHD }\end{array}$ & $\begin{array}{c}0.733 \pm 0.12 \\
n=3\end{array}$ & $\begin{array}{c}0.675 \pm 0.05 \\
n=4\end{array}$ & 0.499 \\
\hline $\begin{array}{l}\text { IMT in patients } \\
\text { with CVA/TIA }\end{array}$ & $\begin{array}{c}0.91 \pm 0.32 \\
(n=10)\end{array}$ & $\begin{array}{c}0.6 \\
(n=1)\end{array}$ & - \\
\hline
\end{tabular}

IMT - Intima-media thickness

Table 3: Relation of IMT to smoking, diabetes, and hypertension among patients and controls

\begin{tabular}{lccc}
\hline Group & Cases $\mathrm{n}=60$ & Controls $\mathrm{n}=50$ & $P$ value \\
\hline Smokers & $0.83 \pm 0.21$ & $0.59 \pm 0.074$ & $<0.0001$ \\
Nonsmokers & $0.76 \pm 0.11$ & $0.595 \pm 0.10$ & $<0.0001$ \\
Diabetics & $0.818 \pm 0.21$ & $0.63 \pm 0.08$ & 0.0179 \\
Nondiabetics & $0.775 \pm 0.19$ & $0.585 \pm 0.1$ & $<0.001$ \\
Hypertensives & $0.88 \pm 0.26$ & $0.61 \pm 0.11$ & 0.013 \\
Normotensives & $0.762 \pm 0.172$ & $0.59 \pm 0.096$ & $<0.0001$ \\
\hline
\end{tabular}

IMT - Intima-media thickness
The IMT was significantly increased in smoker and nonsmoker, diabetic and nondiabetic, hypertensive and nonhypertensive among the cases compare to controls [Table 3].

Carotid plaques were present in 18 patient with stroke when compared to 7 in controls $(P=0.067)$. The number plaques was higher among patients with diabetes $(33.67 \%)$, hypertension $(70 \%)$, and smoking $(40 \%)$. The corresponding Figures among controls were $10 \%$ in diabetics, $12.5 \%$ in hypertensives, and $10 \%$ among smokers [Table 4]. The difference between the two groups was significant in regard to hypertension $(P=0.019)$. Patients with carotid plaque had significantly increased IMT $(0.95 \pm 0.22)$ when compared to patients without plaques $(0.71 \pm 0.12)$ $(P<0.001)$. The lipid fractions were measured in both the patients and the controls and the differences were not significant [Table 5].

In the absence of a well-defined population cut-off value for IMT, we used control mean IMT plus two standard deviations. The IMT value thus calculated was $0.79 \mathrm{~mm}$. Such a value would include $95 \%$ of the controls. Of the 60 patients, 29 patients had an IMT above $0.79 \mathrm{~mm}$ while 31 had an IMT below this cut-off value. As expected, only two subjects among the controls had IMT above this value. The sensitivity of this value was $48.33 \%$, while the specificity was $96 \%$. The positive predictive value was $93.55 \%$, while the negative predictive value was $60.76 \%$.

\section{Discussion}

In the present study the IMT was significantly more in patients with acute ischemic stroke when compared to controls and this difference persisted across all age groups. The mean IMT in our study was $0.792 \mathrm{~mm}$,

\begin{tabular}{lcc}
\hline \multicolumn{3}{l}{ Table 4: Distribution of plaques among patients and controls } \\
\hline Patient groups having & Cases $(n=60)$ & $\begin{array}{c}\text { Controls }(n=50) \\
\text { plaques }\end{array}$ \\
\hline Overall number & $(\%)$ & $7 / 50(14)$ \\
Diabetic patients & $18 / 60(30)$ & $1 / 10(10)$ \\
Hypertensive patients & $4 / 11(36.4)$ & $1 / 8(12.5)$ \\
Smokers & $7 / 10(70)$ & $1 / 10(10)$ \\
\hline
\end{tabular}

Table 5: Lipid profile in patients and controls

\begin{tabular}{lccc}
\hline Lipid fraction & Cases $(\mathrm{n}=60)$ & $\begin{array}{c}\text { Controls } \\
(\mathrm{n}=50)\end{array}$ & P value \\
\hline Cholesterol $(\mathrm{mg} / \mathrm{dl})$ & $171.27 \pm 31.02$ & $165.48 \pm 37.46$ & 0.386 \\
Triglycerides $(\mathrm{mg} / \mathrm{dl})$ & $130.3 \pm 33.15$ & $132.24 \pm 41.76$ & 0.791 \\
HDL $(\mathrm{mg} / \mathrm{dl})$ & $41.35 \pm 6.19$ & $38.86 \pm 6.35$ & 0.0408 \\
LDL $(\mathrm{mg} / \mathrm{dl})$ & $115.67 \pm 19.98$ & $102.26 \pm 25.47$ & 0.0032 \\
VLDL $(\mathrm{mg} / \mathrm{dl})$ & $23.25 \pm 5.17$ & $23.94 \pm 6.79$ & 0.5567 \\
\hline
\end{tabular}


which is similar to the values reported in other Indian studies ${ }^{[6]}$ but lower than the reported value from the developed countries. ${ }^{[7,8]}$ The mean IMT in the study by Mukherjee et al., from Kolkatta was $0.66 \mathrm{~mm}$ in patients with stroke and 0.32 in the controls. In this study the sample size was small and the controls were not matched by the risk factors. ${ }^{[6]}$ In the Italian study by Cupin et al., ${ }^{[7]}$ the mean IMT was $1.04 \mathrm{~mm}$ in patients with nonlacunar stroke and $0.91 \mathrm{~mm}$ in patients with lacunar strokes. In the control subjects it was $0.91 \mathrm{~mm}$. The baseline characteristics of the patient population was some what similar to our study except for age, the mean age in this study was approximately 70 years, This study also found greater correlation of CCA-IMT with nonlacunar compared to lacunar strokes. In the study by Pruissen et al., ${ }^{[8]}$ the mean IMT was $1.08 \mathrm{~mm}$ and the age of the patient population was 63 years. They have also found a significant difference in the IMT value between patients with large vessel disease and small vessel disease. Onbas et al., ${ }^{[9]}$ reported increased mean IMT in the artery ipsilateral to the brain infarct when compared to the contralateral artery. ${ }^{[9]}$ The mean IMT in the artery ipsilateral to the brain infact was $1.02 \mathrm{~mm}$. In the Étude du Profil Génétique de l'Infarctus Cérébral (GÉNIC) Case-Control Study the mean IMT was $0.797 \mathrm{~mm}$ in stroke patients and $0.735 \mathrm{~mm}$ in controls. ${ }^{[10]}$ The base-line clinical characteristics in this study were similar to our study population except for higher age and hypertension.

Our study has some limitations, it was a single-center study done in a tertiary care hospital. The sample size was small and did not have adequate numbers to analyze the effect of some the risk factors. Our study was not a prospective study and could not calculate hazard ratios for IMT values. We could not study the progression of IMT.

\section{References}

1. Abhinav Goyal, Salim Yusuf. The burden of cardiovascular disease in the Indian subcontinent. Indian J Med Res 2007;124:235-44.

2. Smith WS, Johnston SC, Easton DJ. Cerebrovascular diseases. In: Kasper DL, Braunwald E, Fauci AS, Hauser SL, Longo DL, Jameson LJJ, editors. Harrison's principles of Internal Medicine. $16^{\text {th }} \mathrm{ed}$. McGraw-Hill Companies; 2005. p. 2372-93.

3. Libby P. Prevention and treatment of atherosclerosis. In: Kasper DL, Braunwald E, Fauci AS, Hauser SL, Longo DL, Jameson JL, editors. Harrison's principles of Internal Medicine. 16th ed. MeGraw-Hill Companies; 2005. p. 1430-3.

4. De Silva DA, Woon FP, Lee MP, Chen CP, Chang HM, Wong MC. South Asian patients with ischemic stroke intracranial large arteries are the predominant site of disease. Stroke 2007;38:2592-4.

5. Pignoli P, Tremoli E, Poli A, Oreste P, Paoletti R. Intimal plus medial thickness of the arterial wall: A direct measurement with ultrasound imaging. Circulation 1986;74:1399-406.

6. Mukherjee SC, Basu AK, Bandyopadhyay R, Pal SK, Mandal SK, et al. Correlation of lipid profile and carotid artery plaque as detected by doppler ultrasound in ischemic stroke patients: A hospital-based study. J Indian Med Assoc 2006;104:325-6.

7. Cupini LM, Pasqualetti P, Diomedi M, Vernieri F, Silvestrini M, Rizzato B, et al. Carotid artery intima-media thickness and lacunar versus nonlacunar infarcts. Stroke. 2002; 33: 689-94.

8. Pruissen DM, Gerritsen SA, Prinsen T.J, Dijk JM, Kappelle LJ, Algra A, et al. Carotid intima-media thickness is different in large- and small-vessel ischemic stroke: The SMART study. Stroke 2007;38:1371-3.

9. Onbas O, Kantarei M, Okur A, Bayraktutan U, Edis A, Ceviz N. Carotid intima-media thickness: Is it correlated with stroke side? Acta Neurol Scand 2005;111:169-71.

10. Touboul PJ, Elbaz A, Koller C, Lucas C, Adraï V, Chédru F, et al. Common carotid artery intima-media thickness and brain infarction: The Étude du Profil Génétique de l'Infarctus Cérébral (GÉNIC) CaseControl Study. Circulation 2000;102:313-8.

Accepted on 02-07-2009

Source of Support: Nil, Conflict of Interest: None declared. 